\title{
"Late presenters" after paracetamol self poisoning
}

\author{
Martin P Bradley, Jonathan S Nguyen-Van-Tam, James C G Pearson
}

The popularity of paracetamol as a drug for self poisoning has increased dramatically since the early $1980 \mathrm{~s}^{12}$; nowadays almost $50 \%$ of episodes of self poisoning presenting to hospital involve the ingestion of paracetamol or paracetamol containing drugs. ${ }^{3-5}$ It is estimated that about 70000 episodes of paracetamol self poisoning occur each year in Britain. ${ }^{6}$ Although serious morbidity and deaths are rare, ${ }^{67}$ these usually result from late presentation, which reduces the effectiveness of available antidotes. $^{89}$ The epidemiology of paracetamol self poisoning has not previously been described in detail in relation to recorded delays in presentation for treatment. We studied, retrospectively, all episodes of paracetamol self poisoning occurring at either of the two acute hospital units in Nottingham during the first six months of 1996. These included patients seen only in the accident and emergency department, as well as those admitted for inpatient care.

\section{Methods and results}

In Nottingham all patients presenting with suspected or confirmed self poisoning involving paracetamol undergo testing for plasma paracetamol concentrations. The results are routinely recorded in a computerised laboratory database from which all positive tests $(>5$ $\mathrm{mg} / \mathrm{l}$ ) were identified and subsequently confirmed by reference to the clinical records of each person. During the first six months of 1996 we noted 417 episodes involving 361 people; data on time of ingestion and presentation were available for 330 episodes $(79.1 \%)$ involving 294 people $(81.4 \%)$. To avoid bias caused by repeat attenders, only the first presentation by each person during the study period was used in the analysis. Persons in whom the time of ingestion was unknown were more likely to be male ( $51 \%$ versus $42 \%$ ) but this difference was not significant $\left(\chi^{2}=1.9\right.$ with $1 \mathrm{df}, \mathrm{p}=0.17)$. Similarly, no significant differ- ences were detected with respect to age group $\left(0-24\right.$ years versus $25-44$ versus $\geqslant 45: \chi^{2}=2.0$ with $2 \mathrm{df}, \mathrm{p}=0.37$ ); however, persons were more likely to be admitted to hospital when time of ingestion was unknown $(67 \%$ versus $42 \%, \chi^{2}=14.1$ with $\left.1 \mathrm{df}, \mathrm{p}=0.0002\right)$. It was not possible to compare the amounts ingested by these two groups, because of the large number of cases in which both time and amount were unknown. In 132 of 361 cases $(36.6 \%)$ paracetamol was ingested as a constituent of a fixed ratio combination product, in 110 cases $(30.5 \%)$ together with other separate pharmaceutical products, and in 133 cases $(36.8 \%)$ with alcohol.

Serum paracetamol concentrations measured less than four hours after ingestion are unlikely to represent peak concentration; therefore unless the amount ingested has been very large or the time of ingestion cannot be determined, treatment is not started until the four hour concentration is known. Accordingly, we designated presentation times within four hours as "optimal", but any longer than this as potentially delaying the onset of effective treatment. While we found that the majority of patients who had taken a paracetamol overdose $(71.1 \%)$ presented within four hours of ingestion, men were more likely to present later (table 1); however no differences were apparent by age group (0-24 years versus $25-44$ versus $\geqslant 45: \chi^{2}=8.3$ with $6 \mathrm{df}, \mathrm{p}=0.22$ ).

In 263 of the first presentations the amount of paracetamol ingested could be reliably ascertained; the median dose of paracetamol ingested was 9.5 grams. After normalising the amounts by taking logarithms, multiple linear regression was used to investigate the relation of sex and delay to the amount ingested. In the final model, delay was represented by the four clinically relevant categories shown in table 1 , because the use of the detailed continuous values did not significantly improve the model. There was a significant trend of increasing dose
Division of Public

Health Medicine and

Epidemiology, School

of Community Health

Sciences, University of

Nottingham Medical

School, Queen's

Medical Centre,

Nottingham NG7 2UH

Correspondence to:

Dr Van-Tam.

Accepted for publication 28 June 1998

Table 1 Differences in sex, intravenous therapy, hospital admission and amount of paracetamol ingested in relation to time delay between ingestion and presentation to hospital

\begin{tabular}{|c|c|c|c|c|c|c|c|c|c|c|c|}
\hline & Time & betwee & inge. & stion a & d pre & sentati & $n(h)$ & & & & \\
\hline & $0-4$ & & $>4$ & & $>8$ & & $>12$ & & Total & & Test and significance \\
\hline No in group & 209 & & 41 & & 19 & & 25 & & 294 & & \\
\hline Male & 75 & (61) & 23 & (19) & 8 & (7) & 16 & (13) & 122 & $(100)$ & $\chi^{2}: p=0.009$ \\
\hline Female & 134 & (78) & 18 & (11) & 11 & (6) & 9 & (5) & 172 & $(100)$ & \\
\hline IV antidote & & & & & & & & & & & \\
\hline Yes & 33 & (16) & 7 & $(17)$ & 9 & $(47)$ & 12 & $(48)$ & 61 & (21) & $\chi^{2}$ for trend $: p<0.000005$ \\
\hline No & 176 & (84) & 34 & (83) & 10 & (53) & 13 & (52) & 233 & (79) & \\
\hline Admitted & & & & & & & & & & & \\
\hline Yes & 78 & $(37)$ & 18 & $(44)$ & 11 & $(58)$ & 16 & $(64)$ & 123 & $(42)$ & $\chi^{2}$ for trend $: p=0.003$ \\
\hline No & 131 & (63) & 23 & (56) & 8 & (42) & 9 & (36) & 171 & (58) & \\
\hline Paracetamol $(\mathrm{g})$ inge & & & & & & & & & & & \\
\hline No in group & 191 & & 32 & & 19 & & 21 & & 263 & & \\
\hline Median & 9.0 & & 9.4 & & 10.5 r & & 12.5 & & 9.5 & & Multiple regression trend $: p=0.003$ \\
\hline Geometric mean & 8.9 & & 9.8 & & 12.1 & & 14.2 & & 9.5 & & \\
\hline
\end{tabular}

Percentages shown in parentheses. 
with increased delay in presentation ( $\mathrm{p}=$ 0.003). After adjusting for sex differences, the relative increase in the geometric mean of the amount ingested was 1.16 (95\% CI 1.05 to 1.27) for each period of delay. Although there was a suggestion that the trend may have been stronger in men than women, the small number of women with long delays made the comparison inconclusive. The geometric mean for women was 0.90 (95\% CI 0.75 to 1.08$)$ that of men, after adjusting for time since ingestion.

Those who delayed presenting were more likely to require intravenous therapy and hospital admission. No patients died during the study period. Only one patient was admitted to a high dependency area, after a delay of 2.25 hours between ingestion and presentation, and was discharged home two days later.

\section{Comment}

Men more than women placed themselves at increased risk by waiting more than four hours before presenting for treatment after paracetamol self poisoning. This was not because of an inability to seek help as no patients in our series were found unconscious. Furthermore, this finding was not because of extreme overdose in a small sub-group of "late presenters" (data available on request). Our data are consistent with the known epidemiological differences between patients who attempt suicide and those who successfully complete it $^{10}$; the former are more likely to be women who act in situations that increase the likelihood of detection or intervention, whereas the latter are more likely to be men who act in isolation to complete the suicide.

The median dose of paracetamol ingested was relatively small, albeit still dangerous (9.5 grams $=19$ tablets) suggesting an element of impulse and opportunistic use in many episodes of self poisoning. ${ }^{36}$ Therefore the new UK regulations, due for implementation in
September 1998, limiting the amount of paracetamol that can be purchased from nonpharmacy outlets to 8.0 grams ( 16 tablets) may have little effect in reducing further the amount of drug consumed during many self poisonings. ${ }^{11} 12$

Health professionals should be aware that "late presenters" after paracetamol self poisoning are likely to have ingested a larger quantity of drug and may have deliberately delayed seeking help. They are thus more likely to require the initiation of intravenous therapy that necessitates hospital admission. ${ }^{9}$

Funding: none

Conflicts of interest: none

1 Hawton K, Fagg J. Trends in deliberate self poisoning and self injury in Oxford, 1976-90. BMF 1992;304:1409-11.

2 McLoone P, Crombie IK. Hospitalisation for deliberate self-poisoning in Scotland from 1981 to 1993: trends in rates and types of drugs used. Br f Psychiatry 1996;169:81-

3 Hawton K, Ware C, Mistry H, et al. Paracetamol self-poisoning characteristics, prevention and harm reduction. Br f Psychiatry 1996;168:43-8.

4 Thomas SH, Bevan L, Bhattacharyya S, et al. Presentation of poisoned patients to accident and emergency departof poisoned patients to accident and emergency depart1996;15:466-70.

5 Bialas MC, Reid PG, Beck P, et al. Changing patterns of self-poisoning in a UK health district. $Q \mathcal{F}$ Med 1996;89: 893-901

6 Fagan E, Wannan G. Reducing paracetamol overdoses. $B M \mathcal{1 9 9 6 ; 3 1 3 : 1 4 1 7 - 1 8}$

7 Spooner JB, Harvey JG. Paracetamol overdosage-facts not misconceptions. Pharm f 1993;250:706-7.

8 Harrison PM, Keays R, Bray GP, et al. Improved outcome of paracetamol-induced fulminant hepatic failure by late administration of acetylcysteine. Lancet 1990:335:1572-3.

9 Thomas SH, Horner JE, Chew K, et al. Paracetamol poisoning in the north east of England: presentation, early management and outcome. Hum Exp Toxicol 1997;16:495500.

10 Gunnell DJ, Peters TJ, Kammerling RM, Brooks J. Relation between parasuicide, suicide, psychiatric admissions, and between parasuicide, suicide, psychiatric admissions,
socio-economic deprivation. BMF 1995;311:226-30.

11 Gunnell D, Hawton K, Murray V, et al. Use of paracetamol for suicide and non-fatal poisoning in the UK and France: are restrictions on availability justified? $\mathcal{f}$ Epidemiol Community Health 1997;51:175-9.

12 Medicines Control Agency. Statutory Instrument no. 2045. The Medicines (sale or supply) (miscellaneous provisions) Amendment (no 2) Regulations 1997. London: Stationery Office, 1997. 